\title{
Kepercayaan Publik (Public Trust) Terhadap E-Government : Studi Kasus Penggunaan E-Mobile BPJS Kesehatan Di Kota Makassar
}

\author{
${ }^{1}$ Sitti Mirsa Sirajuddin, ${ }^{2}$ A. Atrianingsi \\ ${ }^{12}$ Program Studi Ilmu Pemerintahan, Fakultas Ilmu Sosial dan Ilmu Politik, \\ Universitas Indonesia Timur Makassar, Indonesia, 90222 \\ E-mail: sitti.mirsa@uit.ac.id ; atrianingsi_090510606@uit.ac.id
}

Received: 24 Februari 2020; Revised: 16 Maret 2020; Accepted: 17 April 2020

\begin{abstract}
The general objective of the study was to analyze the level of public trust (citizen trust) of e-government based health insurance services, namely the e-mobile National Health Insurance (JKN) BPJS in Makassar City.The design of this research is a quantitative descriptive type. The population in this study were people who used the National Health Insurance (JKN) e-mobile application with 167 respondents. Data collection was carried out using a questionnaire instrument. Data analysis uses multiple linear regression.The results showed that first there was a high level of public trust in JKN emobile applications. This means that the application gives satisfaction to the community and is considered beneficial for them. Secondly, the level of public trust is high in the government, where the public considers the government to be serious in providing health insurance services.
\end{abstract}

Keywords: Public Trust; Health Insurance; E-Mobile JKN

\begin{abstract}
Abstrak
Tujuan umum penelitian adalah untuk menganalisis tingkat kepercayaan publik (citizen trust) terhadap pelayanan jaminan kesehatan berbasis e-government yaitu e-mobile Jaminan Kesehatan Nasional (JKN) BPJS Kesehatan di Kota Makassar. Desain penelitian ini adalah kuantitatif tipe deskriptif. Populasi dalam penelitian ini adalah masyarakat yang menggunakan aplikasi e-mobile Jaminan Kesehatan Nasional (JKN) dengan jumlah responden sebanyak 383 orang. Pengumpulan data dilakukan dengan menggunakan instrument kuesioner. Analisis data menggunakan regresi linear berganda. Hasil penelitian menunjukkan bahwa, pertama terdapat tingkat kepercayaan tinggi masyarakat terhadap aplikasi e-mobile JKN. Hal ini berarti aplikasi memberi kepuasan kepada masyarakat dan dianggap bermanfaat bagi mereka. Kedua tingkat kepercayaan publik tinggi terhadap pemerintah tinggi, dimana masyarakat menilai pemerintah serius dalam memberikan pelayanan jaminan kesehatan.
\end{abstract}

Kata Kunci : Kepercayaan Publik; Jaminan Kesehatan; E-Mobile JKN

Link DOI : http://dx.doi.org/10.31314/pjia.9.1.55-65.2020 


\section{PENDAHULUAN}

Pada era sekarang ini, teknologi telah berkembang pesat sehingga telah menjadi bagian dari kehidupan sehari-hari manusia. Perkembangan teknologi tersebut tersebut tidak dapat dihindari disebabkan kebutuhan manusia akan sebuah teknologi guna memudahkan aktivitas keseharian yang salah satunya disebabkan oleh karena kebutuhan dalam mengakses sebuah informasi atau layanan.

Salah satu teknologi yang berkembang saat ini adalah teknologi web atau internet sebagai salah satu medianya. Pemanfaatan teknologi ini telah digunakan berbagai kalangan seperti lembaga pemerintah dan perusahaan serta masyarakat secara luas. Dalam konteks penyelenggaraan pemerintahan, adanya penggunaan teknologi diharapkan sebagai solusi dalam memberikan kemudahan akses terhadap pelayanan publik. Kebutuhan akan teknologi tersebut sebagai bentuk usaha pemerintah dalam meningkatkan kualitas pelayanan yang rendah. Hal tersebut terjadi pada semua jenis pelayanan publik seperti barang dan jasa (Sufianti, 2007). Begitupun dalam hal institusi pemerintah memberikan pelayanan, maka yang terpenting adalah bagaimana memberikan bantuan dan kemudahan kepada masyarakat dalam rangka memenuhi kebutuhan dan kepentingannya (Harlinda, 2019). Oleh karena itu merupakan sebuah kemajuan apabila pemerintah mulai dan mampu mengadopsi teknologi tersebut sebagai infrastruktur utama dalam memberikan pelayanan publik. Teknologi informasi (IT) dalam pemerintahan disebut dengan istilah e-Government.

Pelayanan publik merupakan salah satu kewajiban pemerintah dalam tata kelola pemerintahan, dimana masyarakat sebagai kelompok sasaran kebijakan maupun pelayanan pemerintah. Pelayanan yang dimaksud salah satunya adalah pelayanan kesehatan. Oleh karena itu dalam rangka memberikan pelayanan kesehatan yang berkualitas, maka pemerintah memanfaatkan ICT $(e-$ government) guna mempermudah akses publik untuk memperoleh pelayanan kesehatan yang memadai.

Dengan demikian dalam memberikan pelayanan kesehatan berbasis $e$ government yang berorientasi pada publik (public oriented), pemerintah selayaknya mampu memenuhi keinginan yang dibutuhkan atau dikehendaki oleh publik. Selain itu, dalam rangka memperoleh kepercayaan publik (public trust), pemerintah harus meningkatkan kualitas pelayanan kesehatan. Hal tersebut disebabkan karena kepercayaan publik merupakan salah satu dampak dari pelayanan yang diberikan pemerintah, khususnya dalam bidang kesehatan.

Pada perspektif e-government, aksesibilitas dalam menggunakan sebuah aplikasi yang berbasis IT seringkali menjadi penyebab rendahnya keinginan masyarakat untuk menggunakan sebuah teknologi. Adanya hal tersebut dapat mempengaruhi tingkat kepercayaan publik terhadap pelayanan berbasis IT yang diberikan oleh pemerintah. Hal ini disebabkan karena pelayanan yang berkualitas berbanding lurus dengan tingkat kepercayaan publik (public trust).

Penelitian sejenis telah dilakukan antara lain oleh Viky Ferdiansyah (2014) dimana hasil penelitiannya menunjukkan bahwa pengembangan e-government menghasilkan kedekatan dan interaksi atau keterlibatan masyarakat semakin besar, luas dan cepat. Pola interaksi berubah dari one stop service menjadi non-stop service. Namun, Pola pelayanan dalam RW-Net tergantung dari bagaimana budaya kerja organisasi dan kesiapan teknologi serta sumber daya manusia yang dapat mempengaruhi pelaksanaan pemerintahan secara transparan dan dapat dipertanggungjawabkan (Ferdiansyah \& Hidayat, 2014). Penelitian lainnya dilakukan oleh Rahadian (2017) yang menunjukkan bahwa E-Government terbukti mampu meningkatkan kualitas layanan publik dan kepercayaan masyarakat terhadap pemerintah. Namun masih rendahnya tingkat penerimaan dan pemanfaatan layanan e-government pada negara berkembang(Rahadian, n.d.). 


\section{Available Online at http://journal.umgo.ac.id/index.php/Publik Publik (Jurnal Ilmu Administrasi) Vol 9 (1), Juni 2020}

Disamping itu hasil penelitian Anita Wulansari menunjukkan ada tiga faktor yang diukur dalam penentuan kematangan e-government yang berorientasi kepada masyarakat, yaitu lembaga, interaksi, dan layanan online. Model ini diharapkan dapat digunakan sebagai alternatif alat penilaian implementasi e-government yang lebih komprehensif karena mengukur dari tiga sisi, yaitu lembaga pemerintah, interaksi pegawai pemerintah dengan masyarakat, dan layanan e-government yang disediakan.

Pehahaman masyarakat terhadap $e$ government belum dapat menjamin bahwa masyarakat bersedia menggunakannya. Sehingga petensi kerugian dalam investasi e-government akan muncul (Wulansari \& Inayati, 2019). Hasil penelitian Bambang Irawan menunjukkan bahwa penggunaan teknologi informasi dan komunikasi untuk meningkatkan efisiensi dan efektivitas pemerintah, kemudian memungkin publik mengakses informasi dan menjadikan pemerintah lebih akuntabel (Irawan, 2015).

Dalam perspektif e-government, aksesibilitas dalam menggunakan sebuah aplikasi yang berbasis IT seringkali menjadi penyebab rendahnya keinginan masyarakat untuk menggunakan sebuah teknologi. Adanya hal tersebut dapat mempengaruhi tingkat kepercayaan publik terhadap pelayanan berbasis IT yang diberikan oleh pemerintah. Hal ini disebabkan karena pelayanan yang berkualitas berbanding lurus dengan tingkat kepercayaan publik (public trust).

Kepercayaan di definisikan sebagai penilaian kolektif dari satu kelompok atas kelompok lainnya bahwa kelompok tersebut akan bertindak jujur, dapat memenuhi komitmennya dan tidak akan merugikan kelompok lainnya. Definisi ini menegaskan bahwa seorang mitra tidak akan merugikan dan bertentangan dengan harapan mitranya (Park \& Blenkinsopp, 2011). Kepercayaan merupakan suatu keoptimisan dalam situasi rentan dimana truster mempercayai trustee yang akan memperhatikan kepentingan truster dalam artian bahwa ketika individu berada di situasi sulit yang umumnya juga dialami semua orang, individu tersebut optimis bahwa individu lain akan menaruh perhatian pada kebutuhan dan kepentingannya (Hall et al., 2001) Sebagaimana kepercayaan adalah kecenderungan untuk yakin kepada seseorang.

Dalam kaitannya dengan penelitian ini adalah kepercayaan publik terhadap layanan e-government. Keyakinan awal mengacu pada kepercayaan pada trustee tidak familiar. Keyakinan awal diperlukan dalam hubungan di mana warga negara belum memiliki informasi yang kredibel atau bermakna tentang penyedia layanan elektronik (Mcknight et al., 2002) Dalam hubungan awal, seseorang menggunakan informasi apa pun yang mereka miliki, seperti persepsi situs web atau lembaga pemerintah, untuk menilai kepercayaan trustee. Selain itu, kepercayaan sebagian besar di dasarkan pada karakteristik trustor (disposition to trust), asumsi yang dibuat mengenai sifat trustee (trust of the government), dan faktor institusional (trust of the internet (Grazioli \& Jarvenpaa, 2000)

Kepercayaan atau trust pada layanan berbasis e-government terbagi dalam dua dimensi, pertama adalah kepercayaan terhadap pemerintah (trust of the government), dimensi ini merujuk pada kepercayaan terhadap institusi pelaksana egovernment. Kemudian yang kedua adalah kepercayaan terhadap teknologi yang memungkinkan untuk digunakan seperti layanan berbasis internet (trust of the internet(Carter \& Bélanger, 2005). Kedua dimensi tersebut menjadi indikator dalam mengukur kepercayaan (trustworthiness) terhadap keinginan pengguna untuk menggunakan sebuah teknologi (intention to use). Kepercayaan publik, sebagaimana dijelaskan oleh McKnight dapat diukur melalui 2 dimensi, yaitu : a) Kepercayaan terhadap pemerintah dan b) kepercayaan terhadap layanan e-government. Disposisi kepercayaan adalah sejauh mana seseorang menunjukkan kecenderungan untuk bersedia bergantung dan percaya pada orang lain (Mcknight et al., 2002) 


\section{Jurnal IImu Administrasi}

Salah satu bentuk pelayanan jaminan kesehatan yang berbasis e-government yang merupakan bentuk inovasi pemerintah dalam hal ini BPJS Kesehatan adalah e-mobile Jaminan Kesehatan Nasional (JKN). Layanan ini berbasis pada aplikasi yang dapat didownload pada smartphone sehingga dapat digunakan dimanapun. Tujuan aplikasi ini adalah untuk memudahkan masyarakat untuk mengakses pelayanan jaminan kesehatan dimanapun berada.

Menurut data BPJS Kesehatan tahun 2017 pengguna layanan e-mobile JKN seluruh Indonesia lebih dari 1 juta pengguna versi android dan lebih dari 2.000 pengguna versi ios di seluruh Indonesia. Jika dibandingkan dengan jumlah peserta non Penerima Bantuan Iuran (PBI) 47,72 juta se-Indonesia, hal ini menunjukkan bahwa keinginan serta ketertarikan masyarakat untuk menggunakan layanan Jaminan Kesehatan Nasional (JKN) masih tergolong rendah. Oleh karena itu, penelitian ini penting untuk dilakukan agar dapat mengetahui bagaimana tingkat penerimaan masyarakat dan kepercayaan masyarakat selaku pengguna (user) aplikasi tersebut. Dan hal ini pula yang membedakan penelitian ini dengan penelitian terdahulu.

\section{METODE PENELITIAN}

Penelitian ini dilaksanakan di Kota Makassar. Pendekatan dalam penelitian ini adalah kuantitatif dengan tipe deskriptif. Populasi penelitian ini adalah Pekerja Bukan Penerima Upah (PBPU) sebanyak 164.589 orang dan Bukan Pekerja (BP) sebanyak 76.506 orang sehingga total populasi dalam penelitian ini sebanyak 241.095 orang. Jumlah sampel dalam penelitian ini ditentukan dengan menggunakan rumus yang dikembangkan oleh Isaac dan Michael (Sugiyono, 2008), yaitu sebagai berikut :

$$
s=\frac{\lambda^{2} \cdot N \cdot P \cdot Q}{d^{2} \cdot(N-1)+\lambda^{2} \cdot P \cdot Q}
$$

Keterangan :

$\mathrm{s}=$ Jumlah Sampel

$\lambda=$ Taraf Kesalahan $(1,96)$

$\mathrm{N}=$ Besar Populasi

$\mathrm{P}=\mathrm{Q}=0,5$

$\mathrm{d}=$ Derajat Ketepatan 5\% $(0,05)$

Maka besar sampel dalam penelitian

ini adalah sebagai berikut:

$$
s=\frac{\lambda^{2} \cdot N \cdot P \cdot Q}{d^{2} \cdot(N-1)+\lambda^{2} \cdot P \cdot Q}
$$

$S$

$$
\begin{aligned}
& =\frac{(1,96)^{2} \cdot 241.095 \cdot 0,5 \cdot 0,5}{(0,05)^{2} \cdot(241.095-1)+(1,96)^{2} \cdot 0,5 \cdot 0.5} \\
& s=\frac{231.547,638}{603,695} \\
& s=383
\end{aligned}
$$

Jadi jumlah sampel minimum dalam penelitian ini adalah sebanyak 383 orang responden. Sumber data penelitian ini terdiri dari data primer dan data sekunder. Data primer yaitu data yang diambil secara langsung oleh peneliti dari sumbernya yang diperoleh melalui teknik pengumpulan data dengan menggunakan kuesioner. Sedangkan data sekunder diperoleh dari laporan dan telaah dokumen serta instansi yang terkait dengan penelitian ini. Teknik pengumpulan data dalam penelitian ini menggunakan daftar pertanyaan atau kuesioner.

Pengolahan data dilakukan melalui program SPSS untuk menghasilkan informasi yang benar sesuai tujuan penelitian. Tahapan pengolahan data dalam penelitian ini adalah penyuntingan data (editing), pengkodean variabel (coding), memasukkan Data (entry data) dan pembersihan Data (cleaning). Analisis data penelitian menggunakan aplikasi SPSS 21. Hipotesis penelitian ini terdiri dari dua hipotesis, yaitu pertama masyarakat memiliki kepercayaan yang tinggi terhadap aplikasi e-mobile JKN (H1). Kedua masyarakat memiliki kepercayaan yang tinggi terhadap 
pemerintah $(\mathrm{H} 2)$.

\section{HASIL DAN PEMBAHASAN}

Deskripsi karakteristik responden adalah penjelasan tentang identitas pengguna (user) e-mobile JKN. Jumlah responden dalam penelitian disebanyak 383 orang. Pengumpulan data mulai dilaksanakan pada bulan Juli - September 2019. Berikut kami sajikan informasi mengenai identitas diri responden mulai dari jenis kelamin, umur, tingkat Pendidikan pengguna e-mobile JKN. Karakteristik responden berdasarkan jenis kelamin yang diperoleh melalui hasil penelitian kepercayaan publik pengguna (user) e-mobile JKN sebagaimana terlihat pada tabel 1:

Tabel 1. Distribusi Frekuensi

Responden Menurut Jenis Kelamin Pengguna e-mobile JKN

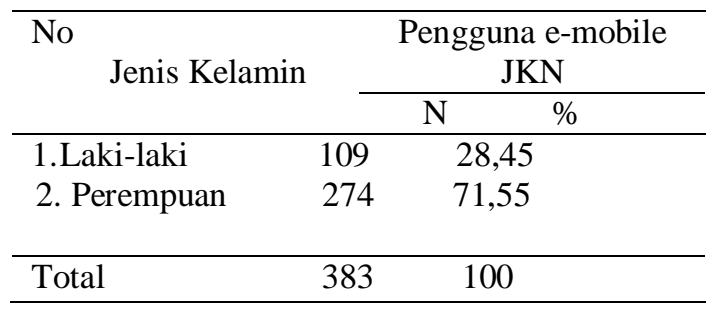

Sumber : Olahan Data Primer, 2019

Berdasarkan tabel 1 menunjukkan bahwa keterlibatan responden selaku pengguna (user) e-mobile JKN dalam penelitian ini didominasi oleh responden yang berjenis kelamin perempuan yaitu sebanyak $71,55 \%$.

Tabel 2.

Distribusi Frekuensi Responden Menurut Umur Pengguna e-mobile JKN

\begin{tabular}{lcrr}
\hline No & Klasifikasi & \multicolumn{2}{c}{ Pengguna e mobile } \\
& Umur & \multicolumn{2}{c}{ JKN } \\
\cline { 3 - 4 } & & 4 & \multicolumn{1}{c}{$\%$} \\
\hline 1 & $<20$ tahun & 239 & 62,40 \\
2 & $21-30$ tahun & 102 & 26,63 \\
3 & $31-40$ tahun & 38 & 9,92 \\
4 & $41-50$ tahun & - & - \\
5 & $>50$ tahun & 383 & 100
\end{tabular}

Sumber : Olahan Data Primer, 2019
Karakteristik responden berdasarkan umur yang diperoleh melalui hasil penelitian kepercayaan publik pengguna (user) e-mobile JKN dapat dilihat pada tabel 2. Berdasarkan tabel 2 menunjukkan bahwa responden terbesar adalah yang berada pada kelompok umur 21 - 30 tahun sebesar $62,40 \%$ yaitu 239 orang dan terendah pada kelompok umur dibawah 20 tahun sebesar $1,05 \%$ sebanyak 4 responden. Hal ini membuktikan bahwa layanan e-government untuk mempermudah layanan publik telah dapat diterima masyarakat meskipun penggunaannya belum maksimal dalam arti sebagian besar pengguna layanan diusia yang tergolong masih muda , dimana berkaitan dengan cara menggunakan serta fasilitas yang harus dimiliki seperti smartphone yang lebih banyak digunakan oleh usia sampai dengan 40 tahun.

Penilaian tingkat kepercayaan aplikasi e-mobile JKN dalam penelitian ini didasarkan pada empat dimensi kepercayaan terhadap teknologi yang digunakan seperti layanan berbasis internet (trust of the internet) (Bélanger \& Carter, 2008), terdiri dari kepercayaan terhadap tampilan aplikasi, kepercayaan terhadap informasi yang ditampilkan, kepercayaan terhadap kemudahan akses dan kepercayaan terhadap manfaat aplikasi. Hasil penelitian dan analisis data terhadap dimensi tersebut menunjukkan hasil sebagaimana ditunjukkan pada tabel 3 .

Berdasarkan tabel 3 tersebut menunjukkan bahwa secara umum kepercayaan terhadap teknologi berbasis internet yaitu e-mobile JKN (trust of the internet) cukup tinggi dari empat indikator trust of the internet. Pertama hasil kepercayaan terhadap tampilan aplikasi menunjukkan bahwa mayoritas responden memiliki kepercayaan yang tinggi terhadap 
tampilan aplikasi sebanyak 219 responden dengan presentase $57,18 \%$.

Tabel 3

Tingkat Kepercayaan terhadap aplikasi emobile JKN (trust of the internet)

\begin{tabular}{|c|c|c|c|c|}
\hline \multirow[t]{2}{*}{ No } & \multirow{2}{*}{$\begin{array}{l}\text { Dimensi } \\
\text { Trust of the } \\
\text { Internet }\end{array}$} & \multirow[b]{2}{*}{ Skala } & \multicolumn{2}{|c|}{ Kota Makassar } \\
\hline & & & $\mathrm{N}$ & $\%$ \\
\hline \multirow[t]{3}{*}{1} & $\begin{array}{l}\text { Kepercayaan } \\
\text { terhadap } \\
\text { tampilan }\end{array}$ & Tinggi & 219 & 57,18 \\
\hline & aplikasi & Rendah & 164 & 42,82 \\
\hline & $\begin{array}{l}\text { Jumlah respc } \\
\text { dan presentas }\end{array}$ & iden (n) & 383 & 100,00 \\
\hline \multirow[t]{3}{*}{2} & $\begin{array}{l}\text { Kepercayaan } \\
\text { terhadap } \\
\text { informasi } \\
\text { yang }\end{array}$ & Tinggi & 251 & 65,53 \\
\hline & ditampilkan & Rendah & 132 & 34,47 \\
\hline & $\begin{array}{l}\text { Jumlah respol } \\
\text { dan presentas }\end{array}$ & $\begin{array}{l}\operatorname{den}(\mathrm{n}) \\
(\%)\end{array}$ & 383 & 100,00 \\
\hline \multirow[t]{3}{*}{3} & $\begin{array}{l}\text { Kepercayaan } \\
\text { terhadap } \\
\text { kemudahan }\end{array}$ & Tinggi & 197 & 51,44 \\
\hline & akses & Rendah & 186 & 48,56 \\
\hline & $\begin{array}{l}\text { Jumlah respo } \\
\text { dan presentas }\end{array}$ & $\begin{array}{l}\operatorname{den}(\mathrm{n}) \\
(\%)\end{array}$ & 383 & 100,00 \\
\hline \multirow[t]{3}{*}{4} & $\begin{array}{l}\text { Kepercayaan } \\
\text { terhadap }\end{array}$ & Tinggi & 245 & 63,97 \\
\hline & $\begin{array}{l}\text { manfaat } \\
\text { aplikasi }\end{array}$ & Rendah & 138 & 36,03 \\
\hline & $\begin{array}{l}\text { Jumlah respo } \\
\text { dan presentas }\end{array}$ & $\begin{array}{l}\operatorname{den}(\mathrm{n}) \\
(\%)\end{array}$ & 383 & 100,00 \\
\hline
\end{tabular}

Kedua kepercayaan terhadap informasi yang ditampilkan menunjukkan hasil dimana mayoritas responden percaya terhadap informasi yang ditampilkan oleh aplikasi e-mobile JKN dengan jumlah 251 responden dan presentase sebesar 65,53\%. Ketiga, kepercayaan terhadap kemudahan akses aplikasi e-mobile JKN menunjukkan bahwa responden yang menilai tinggi sebanyak 197 orang dengan presentase $51,44 \%$. Keempat kepercayaan terhadap manfaat aplikasi menunjukkan mayoritas responden memiliki kepercayaan yang tinggi terhadap manfaat dari aplikasi emobile JKN dengan jumlah 245 orang dan presentase $63,97 \%$.
Penilaian tingkat kepercayaan terhadap pemerintah dalam penelitian ini didasarkan pada empat dimensi trust to the government yaitu kepercayaan terhadap aplikasi, kepercayaan terhadap kerahasiaan data, kepercayaan terhadap jaminan kesehatan dan kepercayaan terhadap pelayanan jaminan kesehatan. Hasil pengolahan data dan analisis data dimensi kepercayaan terhadap pemerintah (trust of the government) dapat dilihat pada tabel 4.

Tabel 4

Tingkat Kepercayaan terhadap pemerintah (trust of the government)

\begin{tabular}{|c|c|c|c|c|}
\hline \multirow[t]{2}{*}{ No } & \multirow{2}{*}{$\begin{array}{l}\text { Dimensi } \\
\text { Trust of the } \\
\text { Internet }\end{array}$} & \multirow[b]{2}{*}{ Skala } & \multicolumn{2}{|c|}{ Kota Makassar } \\
\hline & & & $\mathrm{N}$ & $\%$ \\
\hline \multirow[t]{3}{*}{1} & $\begin{array}{l}\text { Kepercayaan } \\
\text { terhadap } \\
\text { aplikasi } \\
\text { jaminan }\end{array}$ & Tinggi & 206 & 53,79 \\
\hline & kesehatan & Rendah & 177 & 46,21 \\
\hline & $\begin{array}{l}\text { Jumlah respo } \\
\text { dan presentas }\end{array}$ & $\begin{array}{l}\text { iden (n) } \\
(\%)\end{array}$ & 383 & 100,00 \\
\hline \multirow[t]{3}{*}{2} & $\begin{array}{l}\text { Kepercayaan } \\
\text { terhadap } \\
\text { kerahasiaan } \\
\text { data pribadi } \\
\text { pengguna }\end{array}$ & Tinggi & 195 & 50,91 \\
\hline & (user) & Rendah & 188 & 49,09 \\
\hline & $\begin{array}{l}\text { Jumlah respor } \\
\text { dan presentas }\end{array}$ & $\begin{array}{l}\operatorname{den}(\mathrm{n}) \\
(\%)\end{array}$ & 383 & 100,00 \\
\hline \multirow[t]{3}{*}{3} & $\begin{array}{l}\text { Kepercayaan } \\
\text { terhadap } \\
\text { pembiayaan } \\
\text { jaminan }\end{array}$ & Tinggi & 251 & 65,54 \\
\hline & kesehatan & Rendah & 132 & 34,46 \\
\hline & $\begin{array}{l}\text { Jumlah respor } \\
\text { dan presentas }\end{array}$ & $\begin{array}{l}\operatorname{den}(\mathrm{n}) \\
(\%)\end{array}$ & 383 & 100,00 \\
\hline \multirow[t]{4}{*}{4} & $\begin{array}{l}\text { Kepercayaan } \\
\text { terhadap }\end{array}$ & Tinggi & 239 & 62,40 \\
\hline & $\begin{array}{l}\text { Pelayanan } \\
\text { jaminan }\end{array}$ & & & \\
\hline & kesehatan & Rendah & 144 & 37,60 \\
\hline & $\begin{array}{l}\text { Jumlah respor } \\
\text { dan presentas }\end{array}$ & $\begin{array}{l}\operatorname{den}(\mathrm{n}) \\
(\%)\end{array}$ & 383 & 100,00 \\
\hline
\end{tabular}

Tabel 4 menunjukkan bahwa secara umum tingkat kepercayaan terhadap pemerintah cukup tinggi dari keempat indikator trust of the government. Pertama tingkat kepercayaan terhadap aplikasi jaminan kesehatan menunjukkan bahwa 
mayoritas responden memiliki kepercayaan yang tinggi terhadap aplikasi e-mobile JKN yang diterbitkan oleh BPJS Kesehatan sebanyak 206 responden dengan presentase $53,79 \%$. Kedua kepercayaan terhadap kerahasiaan data pribadi pengguna (user) menunjukkan hasil dimana mayoritas responden percaya terhadap kerahasiaan data pribadi dengan jumlah 195 responden dan presentase sebesar 50,91\%. Ketiga, kepercayaan terhadap kepercayaan terhadap pembiayaan jaminan kesehatan BPJS Kesehatan menunjukkan bahwa responden yang menilai tinggi sebanyak 251 orang dengan presentase $65,54 \%$. Keempat kepercayaan terhadap pelayanan jaminan kesehatan menunjukkan mayoritas responden memiliki kepercayaan yang tinggi terhadap pelayanan jaminan kesehatan dengan jumlah 239 orang dan presentase $62,40 \%$.

Berdasarkan hasil pengolahan dan analisis data penelitian terkait dua dimensi kepercayaan yaitu kepercayaan terhadap aplikasi internet (trust of the internet) dan kepercayaan terhadap pemerintah (trust of the government), sebagaimana konsep dari Carter \& Bélanger yang telah dijelaskan terdahulu bahwa kedua dimensi tersebutlah yang menjadi indikator dalam mengukur kepercayaan (trustworthiness) pengguna dalam hal ini masyarakat/public untuk menggunakan sebuah teknologi (intention to use). Sejalan dengan hal itu hasil penelitian menunjukkan bahwa: Pertama, kepercayaan terhadap aplikasi e-mobile JKN pada faktanya, mayoritas responden mengemukakan kepercayaan yang cukup tinggi kepada aplikasi tersebut. Kedua, dimensi kepercayaan terhadap pemerintah selaku penyedia (provider) juga menunjukkan tingkat kepercayaan yang cukup tinggi menurut responden. Dalam perspektif public trust dalam menggunakan sebuah aplikasi yang berbasis e- government yang disediakan oleh pemerintah seringkali menjadi penyebab rendahnya keinginan publik untuk menggunakannya adalah ketidakpercayaan dan rasa ragu yang dimiliki publik. apa lagi jika berkaitan dengan pelayanan. Hal ini disebabkan karena pelayanan yang berkualitas sejatinya berbanding lurus dengan tingkat kepercayaan publik (public trust).

\section{PENUTUP}

\section{Kesimpulan}

Hasil penlitian menunjukkan bahwa tingkat kepercayaan publik terhadap Badan Penyelenggara Jaminan Sosial (BPJS) Kesehatan selaku provider jaminan kesehatan nasional dalam hal ini adalah pemerintah dan aplikasi e-mobile JKN cukup tinggi pada kedua dimensi yang dianalisis yaitu dimensi trust of the internet dan trust of the government. Dengan demikian dapatlah ditarik kesimpulan bahwa aplikasi memberi kepuasan kepada masyarakat dan dianggap bermanfaat bagi mereka. Selanjtnya tingkat kepercayaan publik tinggi terhadap pemerintah cukup tinggi, dimana masyarakat menilai pemerintah serius dalam memberikan pelayanan jaminan kesehatan. Akan tetapi pada tingkat kepercayaan atas kerahasiaan data pribadi yang presentasenya cukup rentan.

\section{Saran}

Pemerintah dalam hal ini BPJS Kesehatan perlu memberikan jaminan yang memadai terhadap kerahasiaan data pribadi pengguna (user). Meskipun demikian, secara keseluruhan tingkat kepercayaan publik utamanya tingkat penerimaan masyarakat dan kepercayaan masyarakat selaku pengguna (user) aplikasi tersebut cukup tinggi. 


\section{DAFTAR PUSTAKA}

Bélanger, F., \& Carter, L. (2008). Trust and risk in e-government adoption. Journal of Strategic Information Systems, 17(2), 165-176. https://doi.org/10.1016/j.jsis.2007.12. 002

Carter, L., \& Bélanger, F. (2005). The utilization of e-government services: Citizen trust, innovation and acceptance factors. Information Systems Journal, 15(1), 5-25. https://doi.org/10.1111/j.1365-

2575.2005.00183.x

Ferdiansyah, V., \& Hidayat, D. (2014). EGovernment: Study Fenomenologi Rw-Net Sebagai Pelayanan Publik Yang Transparan Dan Akuntabel Dengan Optimalisasi Fungsi E Government. Ilmu Komunikasi, 1, 46.https://ejournal.bsi.ac.id/ejurnal/ind ex.php/jika/article/view/221

Grazioli, S., \& Jarvenpaa, S. L. (2000). Perils of Internet fraud: An empirical investigation of deception and trust with experienced Internet consumers. IEEE Transactions on Systems, Man, and Cybernetics Part A:Systems and Humans., 30(4), 395-410. https://doi.org/10.1109/3468.852434

Hall, M. A., Dugan, E., Zheng, B., \& Mishra, A. K. (2001). Trust in Physicians and Medical Institutions: What Is It, Can It Be Measured, and Does It Matter? Milbank Quarterly, 79(4), 613-639. https://doi.org/10.1111/14680009.00 223

Harlinda, N. (2019). Optimalisasi Pelayanan Publik Dalam Perspektif New Publick Servicepada Badan Pendapatan Daerah Kota Makassar.
Jurnal Ilmiah Pranata Edu, 1(1), 113.

https://doi.org/https://doi.org/10.3609 0/jipe.v1i1.188

Irawan, B. (2015). E-Government Sebagai Bentuk Baru Dalam Pelayanan Publik: Sebuah Tinjauan Teoritik. Jurnal Paradigma, 4(3), 2252-4266.

Mcknight, D. H., Choudhury, V., \& Kacmar, C. (2002). Developing and Validating Trust Measures for $e$ ComMcknight, D. H., Choudhury, V., \& Kacmar, C. (2002). Developing and Validating Trust Measures for eCommerce: An Integrative Typology. April 2014.merce: An Integrative Typology. April 2014.

Park, H., \& Blenkinsopp, J. (2011). The roles of transparency and trust in the relationship between corruption and citizen satisfaction. International Review of Administrative Sciences, 77(2), 254-274. https://doi.org/10.1177/00208523113 99230

Sufianti, E. (2007). Aplikasi eGovernment dalam Meningkatkan Kualitas Pelayanan Publik pada Beberapa Pemerintah Daerah Kota/Kabupaten di Indonesia. Jurnal Ilmu Administrasi: Media Pengembangan Ilmu Dan Praktek Administrasi, 4(4), 3.

Sugiyono. (2008). Metode penelitian pendidikan: (pendekatan kuantitatif, kualitatif dan $R \& D$ ). Alfabeta.

Wulansari, A., \& Inayati, I. (2019). Faktor-faktor kematangan implementasi e-government yang berorientasi kepada masyarakat. Register: Jurnal Ilmiah Teknologi Sistem Informasi, 5(1), 24. 
Available Online at http://journal.umgo.ac.id/index.php/Publik

Publik (Jurnal Ilmu Administrasi) Vol 9 (1), Juni 2020

https://doi.org/10.26594/register.v5i1

.1288 